Communication

\title{
Investigating the Potential of an In-Situ Method for Monitoring the Malting of Barley Using Solid Phase Microextraction with a Portable Gas Chromatography Mass Spectrometry Instrument
}

\author{
Mark D. Hodges and Neil Fitzgerald * (D) \\ Department of Chemistry, Biochemistry \& Physics, Marist College, 3399 North Road, Poughkeepsie, \\ NY 12601, USA; mark.hodges1@marist.edu \\ * Correspondence: neil.fitzgerald@marist.edu; Tel.: +1-845-575-3000
}

Received: 7 November 2020; Accepted: 16 December 2020; Published: 20 December 2020

\begin{abstract}
An improved understanding of the malting process could have a significant impact on the efficient production of quality malt for the brewing industry. Analysis of volatile organic compounds produced during the malting process is one approach towards achieving this goal. In-situ methods avoid the possibility of contamination and chemical changes occurring during sample transport and storage. This paper describes the investigation of an in-situ sampling method for the detection of volatile organic compounds produced during the malting of barley. Solid Phase Microextraction Gas Chromatography Mass Spectrometry (SPME-GC/MS) was used to identify compounds. The investigated method involved the direct exposure of an SPME fiber in the kiln during barley malting. Using this method, compounds including aldehydes, ketones, and esters were detected. Some changes in volatile organic compound composition were observed during the production of pale malt at a commercial malting house.
\end{abstract}

Keywords: solid phase microextraction; gas chromatography mass spectrometry; portable; in-situ; malting

\section{Introduction}

According to the Beer Institute [1], the beer industry in the U.S. employed nearly 2.1 million Americans and had a combined economic impact of more than USD 328 billion in 2018. The recent explosion of small breweries has increased the demand for specialty ingredients including malts. A better understanding the science of malt roasting could be used to increase the efficiency of the malting process. Traditionally, experienced maltsters have monitored the malting process using their sense of smell. Scientifically, we can detect and identify volatile aroma compounds using a Solid Phase Microextraction (SPME) sampling technique combined with Gas Chromatography Mass Spectrometry (GC/MS). This technique has been used previously to detect volatiles in wort [2] and beer $[3,4]$. Monitoring the chemical processes that occur during the roasting phase of malt production has a potential significant impact on the brewing and fermentation industries. Beal and Mottram [5] identified several volatile compounds produced from samples removed from a kiln and transported to a laboratory. Volatile compounds were isolated on a tenax trap and thermally desorbed into a GC/MS. They found that methylbutanals are major contributors to the malt-like aromas of malted barley and tend to increase during the malting process and reduce as Maillard reaction products increase in darker malts. Vandecan et al. [6] used SPME-GC/MS to analyze aroma compounds produced from commercially available specialty malts. They identified compounds including pyrazines, furanones, and branched aldehydes. Dong et al. [7] analyzed volatile compounds produced by barley at various 
stages in the malting process using headspace SPME-GC/MS. Malt samples were obtained from the malt house, freeze-dried, and stored in polyethylene bags at $-20^{\circ} \mathrm{C}$. For analysis, a slurry was created by mixing grain flour with a $20 \%$ sodium chloride solution. The headspace was then sampled.

While these publications indicate the applicability of headspace GC/MS methods for the monitoring of aroma compounds in the malting process, they all use laboratory-based methods. The ability to measure compounds in-situ provides a more direct measurement of the chemistry occurring and avoids contamination and chemical changes that may occur during transportation and storage. In this work, we investigate the potential of an in-situ method for monitoring volatile organic compounds during the malting process incorporating a portable GC/MS. Portable GC/MS instruments have commonly been used in the environmental and forensics fields [8]. The technique has also been used for the study of beverages, for example, in the determination of adulterants in spirits [9] and the fingerprinting of volatile compounds in coffee [10]. To our knowledge, this is the first report of the use of a portable SPME-GC/MS instrument to monitor volatile organic compounds produced in-situ during the malting of barley.

\section{Material and Methods}

\subsection{Analytical Methods}

In the method under investigation, the entire SPME injector (Custodion $65 \mu \mathrm{m}$ DVB/PDMS, PerkinElmer, Inc., Waltham, MA, USA) was placed directly on top of the grain bed in the kiln without the fiber making contact with the grain (Figure 1). The fiber was then exposed to the grain for one hour with the kiln door closed. The same fiber was used for all in-kiln measurements. After the fiber was exposed for one hour, it was removed from the kiln and immediately introduced into the portable GC/MS instrument (PerkinElmer, Inc., Waltham, MA, USA, Torion T-9).

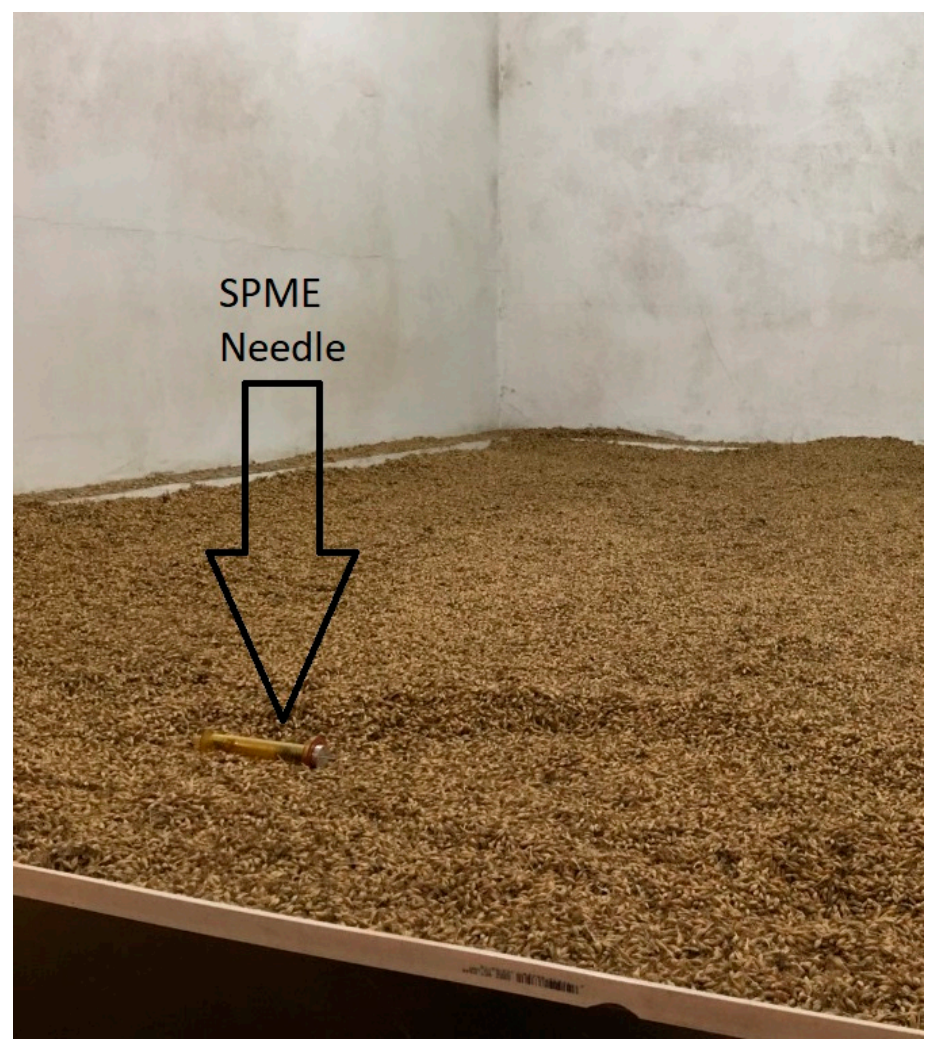

Figure 1. Solid Phase Microextraction (SPME) needle positioned on top of the grain bed in the kiln. 
Measurements were made throughout the kilning process at Hudson Valley Malt (Germantown, NY, USA). Samples were obtained on six occasions (as the temperature was increased from $50{ }^{\circ} \mathrm{C}$ to $52{ }^{\circ} \mathrm{C}$, after heating for $40 \mathrm{~h}$ at $52{ }^{\circ} \mathrm{C}$, after $2 \mathrm{~h}$ at $65^{\circ} \mathrm{C}$, at the end of the $65^{\circ} \mathrm{C}$ heating period, after $2 \mathrm{~h}$ of heating at $76^{\circ} \mathrm{C}$, and as the temperature was increased from 76 to $83^{\circ} \mathrm{C}$ ) over the three-day kilning period in the production of pale malt from a Conlon variety of barley grown in New York State. The kiln temperature ranged from $50{ }^{\circ} \mathrm{C}$ to $83^{\circ} \mathrm{C}$. For comparison purposes, a simplified headspace method was also utilized. Three grains were removed from the kiln whenever the SPME fiber was removed. These grains were ground in a mortar and pestle and placed into a $4 \mathrm{~mL}$ headspace vial. Approximately $2 \mathrm{~mL}$ of $25 \%(\mathrm{~m} / \mathrm{v}) \mathrm{NaCl}$ solution was added. The vial was capped and allowed to equilibrate for $10 \mathrm{~min}$ at room temperature $\left(14^{\circ} \mathrm{C}\right)$. A separate SPME needle (Torion Custodion) was used to pierce the rubber septum and the SPME fiber was exposed to the headspace for $30 \mathrm{~min}$ prior to introduction to the portable GC/MS.

All samples were evaluated using a portable GC/MS (Perkin Elmer, Torion T9) with an MXT-5 Column. The column temperature was held at $50^{\circ} \mathrm{C}$ for $10 \mathrm{~s}$, then increased to $296^{\circ} \mathrm{C}$ at $2{ }^{\circ} \mathrm{C} / \mathrm{s}$ with a final hold time of $47 \mathrm{~s}$. The total run time was $180 \mathrm{~s}$. Significant peaks were not observed at retention times beyond $100 \mathrm{~s}$. The portable GC/MS (Figure 2) is designed specifically for the analysis of volatile and semi-volatile compounds introduced from an SPME fiber or purge and trap needle. The instrument uses an ion trap mass analyzer that has the advantage of being small and therefore easier to maintain under vacuum. It can be made entirely portable with the use of a small helium canister and battery pack. The instrument incorporates a small computer and can also be linked to a laptop to allow more advanced data treatment and library searching. In our case, a NIST (National Institute of Standards and Technology) library (MS Search version 2.0) loaded onto an external laptop computer was used for compound identification.

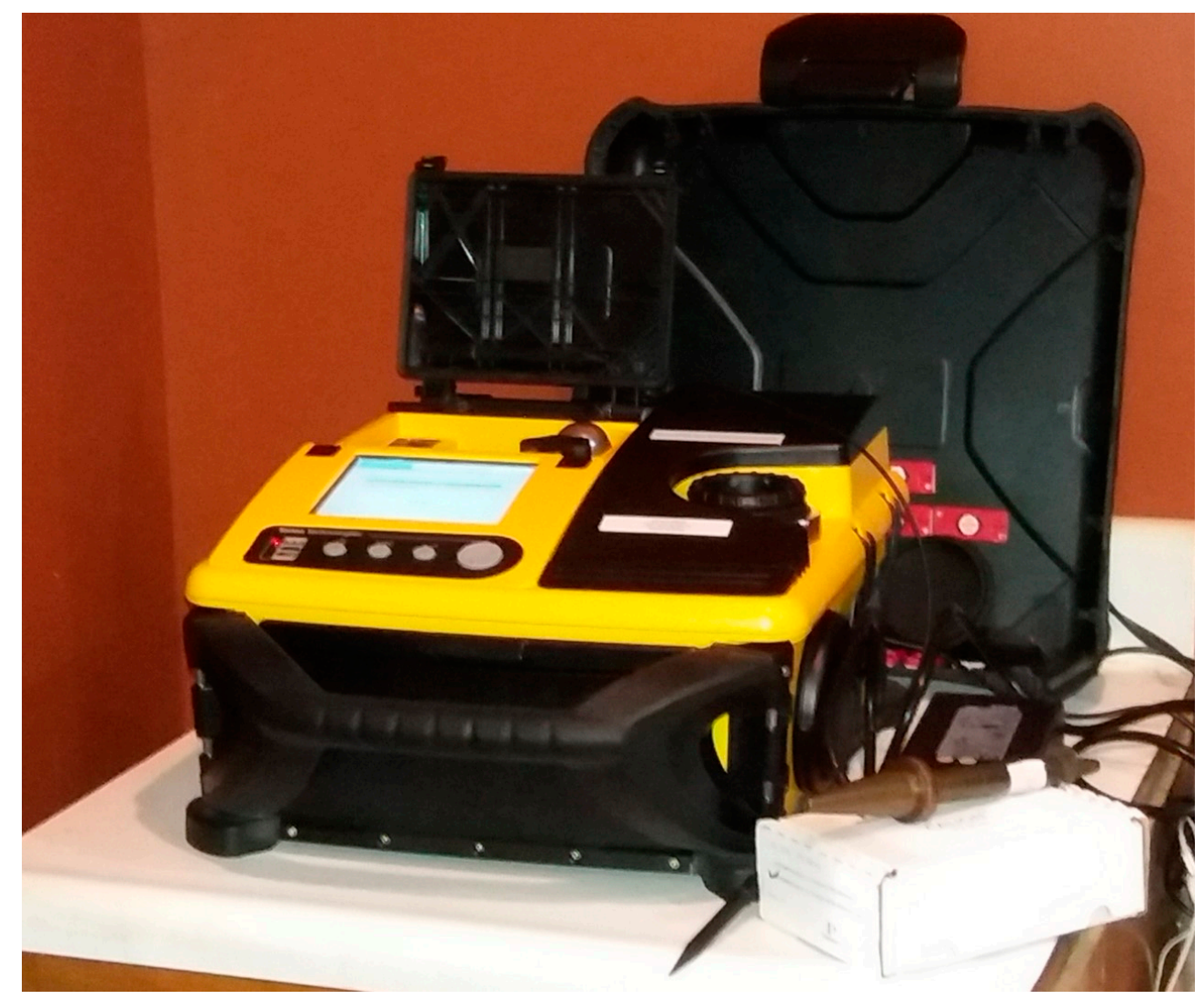

Figure 2. The portable Gas Chromatography Mass Spectrometry (GC/MS) instrument as set up for measurements in the malting house. 


\subsection{Malting Process}

The malt produced during this study is described as a pale malt. The malt was prepared from a locally grown Conlon variety of barley. The moisture content of the barley was increased using a series of steeping cycles as outlined in Table 1 . The steeping process involved periods of submerging the grain in water filled bins, followed by drying periods when the water was removed in a room maintained at $14{ }^{\circ} \mathrm{C}$. Following steeping, the grain was allowed to germinate on a concrete floor at $15^{\circ} \mathrm{C}$ over a $96 \mathrm{~h}$ period with regular raking. The germinated barley was then loaded into a kiln to dry and roast following the temperate program described in Table 1. The grain bed was not mixed during heating.

Table 1. Malting Conditions.

\begin{tabular}{lc}
\hline & \multicolumn{2}{c}{ Steeping Cycles } \\
\hline Time (h) & Grain Environment \\
\hline 8 & Wet \\
\hline 14 & Dry \\
\hline 6 & Wet \\
\hline 12 & Dry \\
\hline 1 & Wet \\
\hline Time (h) & Kilning Conditions \\
\hline 5.5 & Temperature $\left({ }^{\circ} \mathbf{C}\right)$ \\
\hline $41 *$ & 50 \\
\hline 3.25 & 52 \\
\hline 4.5 & 65 \\
\hline 2.25 & 76 \\
\hline$*$ process stalled due to a faulty temperature probe.
\end{tabular}

\section{Results and Discussion}

This method was initially developed in the laboratory and then applied to measurements at the malting house. In the laboratory, it was determined that the SPME fiber had to be exposed for at least an hour in the kiln in order to observe peaks in the GC/MS. Exposure times of less than an hour were found to produce small peaks that could often not be discriminated from the background noise. Exposure times greater than one hour were not found to result in significant improvements, presumably as equilibrium between analyte compounds in the gas phases and retained on the SPME material had been established.

Samples were taken during the roasting phase of a commercial malting house and measured using the developed method. Some of the identified compounds are shown in Table 2. A typical chromatogram is shown in Figure 3. Many of the compounds that were identified were aldehydes. Other oxygen containing compounds (ketones, esters, and alcohols) were identified along with alkanes and a terpene (patchoulene). Several other peaks present in the chromatograms were either identified with lower confidence (less than $90 \%$ matching value in the library search) or observed less often and, therefore, not included in Table 2. Maillard reaction products were not observed, which indicates that the malt produced in this case, a pale malt, was not roasted for sufficient time at a high enough temperature for the Maillard reaction to occur. It is worth noting that additional laboratory-based experiments (results not shown) at higher temperatures were able to identify Maillard reaction products such as 2-methylfuran, furfural, 2-ethyl-3-methylpyrazine, and 2-ethyl-3,5-dimethylpyrazine. 
Statistically significant changes in compound concentrations would require replicate measurements that were not possible given the nature of this work; however, some changes were observed over the roasting period (Figure 4). It is uncertain if these changes are due to chemical reactions or physical processes such as compound volatility. Figure 4 shows nonanal decreasing after reaching a maximum at $65^{\circ} \mathrm{C}$. Patchoulene also decreased after a maximum at $65^{\circ} \mathrm{C}$ while the less volatile pentadecanal increased with an increase in temperature. The results suggest that kiln temperatures could be optimized to obtain the highest amounts of desirable compounds. The comparison headspace method identified similar compounds but failed to detect less volatile analytes (presumably due to the lower sampling temperature). It is also worth noting that some interfering compounds were observed in the headspace method that appear to originate from the septum material.

Table 2. Compounds commonly identified during malting.

\begin{tabular}{ll}
\hline Alkanes & 3-methyl hexane, 4-methyl octane, 3 ethyl-5-(2-ethylbutyl) octadecane \\
\hline Aldehydes & Hexanal, heptanal, nonanal, 2-nonenal, decanal, pentadecanal \\
\hline Ketones & 2-decanone \\
\hline Alcohols & 2-decen-1-ol \\
\hline Esters & eicosanoic acid, phenylmethyl ester \\
\hline Terpenes & patchoulene \\
\hline
\end{tabular}

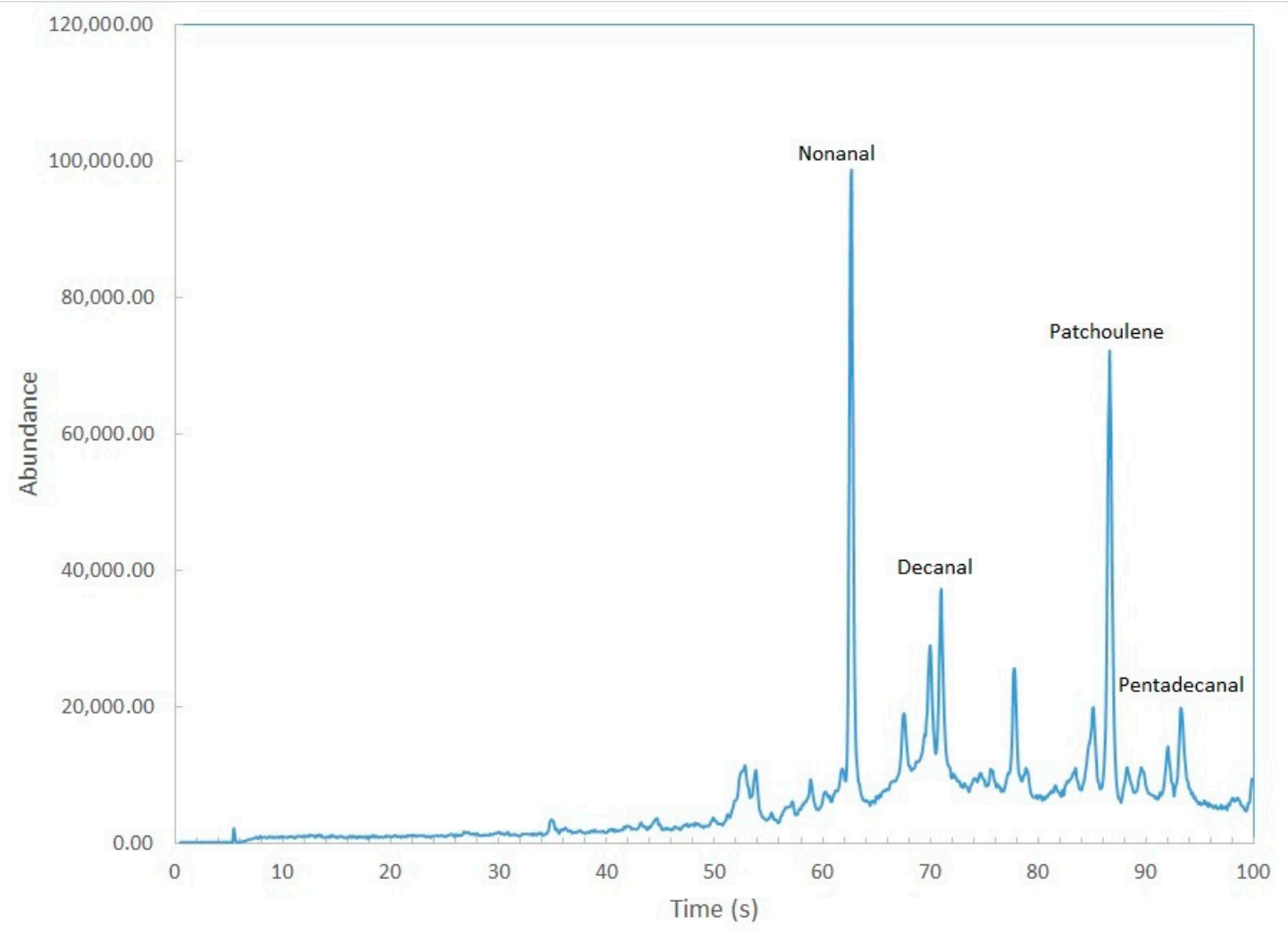

Figure 3. Chromatogram obtained at a kiln temperature of $65^{\circ} \mathrm{C}$. 


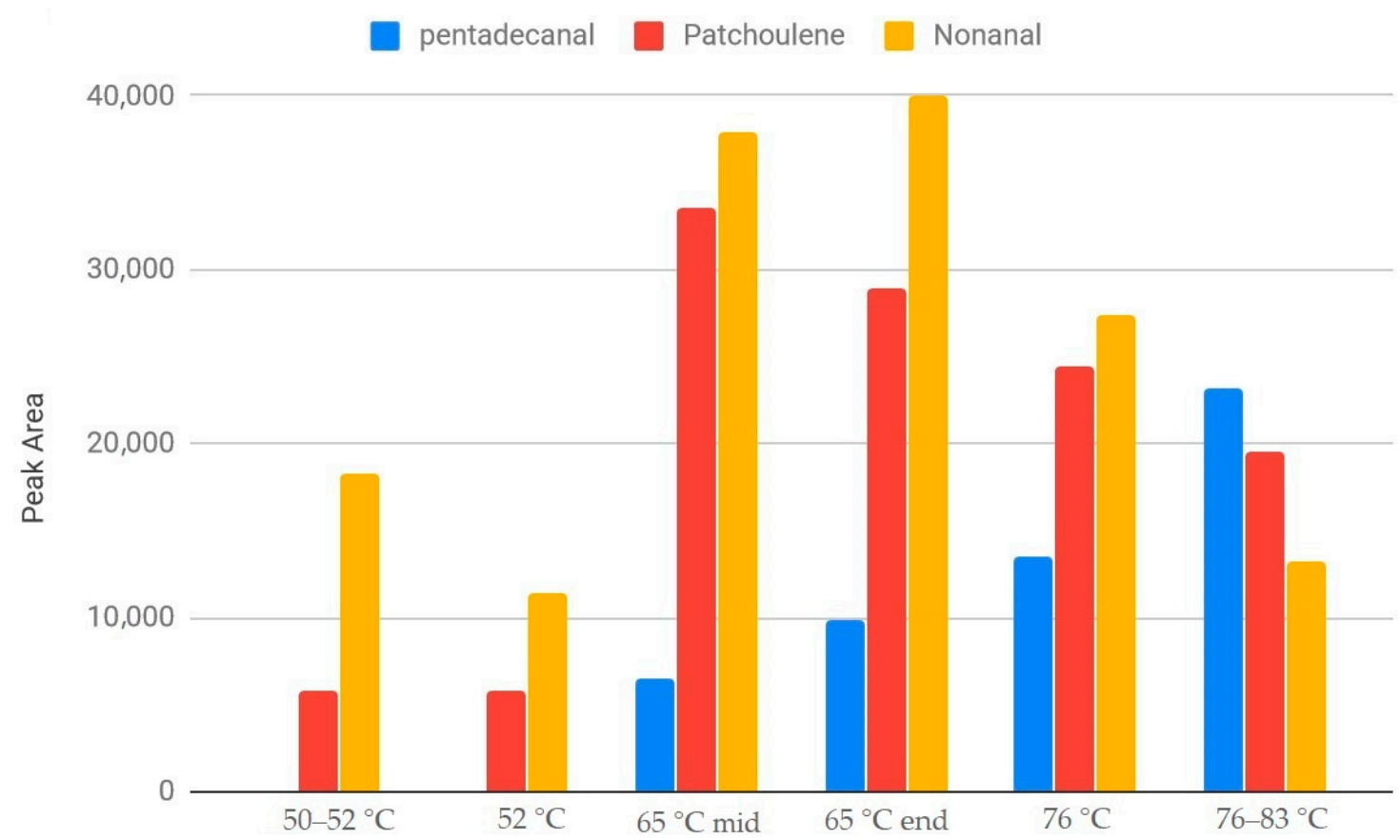

Figure 4. Variation in peak areas of some commonly identified compounds at different temperature stages of malt roasting, i.e., as the temperature was raised from $50{ }^{\circ} \mathrm{C}$ to $52{ }^{\circ} \mathrm{C}$, during the $52{ }^{\circ} \mathrm{C}$ heating stage, mid-way through the $65^{\circ} \mathrm{C}$ heating stage, at the end of the $65^{\circ} \mathrm{C}$ heating stage, during the $76{ }^{\circ} \mathrm{C}$ heating stage, and as the temperature was increased from $76^{\circ} \mathrm{C}$ to $83^{\circ} \mathrm{C}$.

\section{Conclusions}

A totally portable method was successfully developed and applied to in-situ measurements of volatile organic compounds during the roasting of barley malt. Several compounds were identified and changes in abundance for some compounds were observed during the roasting process. This work serves as a proof of concept and demonstrates that it is possible to use this method to observe changes in volatile organic compounds during the kilning process. Reliable quantitative measurements are likely to require the use of internal standards and replicate measurements; however, useful information can be obtained from monitoring changes in compound signals without knowing the absolute concentrations. These results suggest an approach may be possible to optimize the roasting stage in order to maximize the abundance of desirable characteristics in the malt and improve the efficiency of the process.

Author Contributions: M.D.H. performed the majority of the experimental work and assisted in the preparation of the manuscript. N.F. served as the principle investigator and wrote the majority of the manuscript. All authors have read and agreed to the published version of the manuscript.

Funding: Funding for the project was provided by the American Society of Brewing Chemists Research Council. Acknowledgments: The authors wish to acknowledge Hudson Valley Malt for their assistance with the project.

Conflicts of Interest: The authors declare no conflict of interest.

\section{References}

1. Beer Serves America: A Study of the U.S. Beer Industry's Economic Contribution in 2018, A Report Prepared for The Beer Institute. Available online: http://beerservesamerica.org/wp-content/uploads/2019/05/BEERSERVES-AMERICA-A-Study-of-the-U.S.-Beer-Industry\%E2\%80\%99s-Economic-Contribution-in-2018.pdf (accessed on 17 July 2019).

2. De Schutter, D.P.; Saison, D.; Delvaux, F.; Derdelinckx, G.; Rock, J.-M.; Neven, H.; Delvaux, F.R. Characterization of volatiles in unhopped wort. J. Agric. Food Chem. 2008, 56, 246-254. [CrossRef] [PubMed] 
3. Johnson, S.R.; Soprano, S.E.; Wickham, L.M.; Fitzgerald, N.; Edwards, J.C. Nuclear magnetic resonance and headspace solid-phase microextraction gas chromatography as complementary methods for the analysis of beer samples. Beverages 2017, 3, 21. [CrossRef]

4. Kleinová, J.; Klejdus, B. Determination of volatiles in beer using solid-phase microextraction in combination with gas chromatography/mass spectrometry. Czech J. Food Sci. 2014, 32, 241-248. [CrossRef]

5. Beal, A.D.; Mottram, S. Compounds contributing to the characteristic aroma of malted barley. J. Agric. Food Chem. 1994, 42, 2880-2884. [CrossRef]

6. Vandecan, S.M.G.; Saison, D.; Schouppe, N.; Delvaux, F.; Delvaux, F.R. Optimization of speciality malt volatile analysis by headspace solid-phase microextraction in combination with gas chromatography and mass spectrometry. Anal. Chim. Acta 2010, 671, 55-60. [CrossRef] [PubMed]

7. Dong, L.; Piao, Y.; Zhang, X.; Zhao, C.; Hou, Y.; Hou, Y.; Shi, Z. Analysis of volatile compounds from a malting process using headspace solid-phase micro-extraction and GC-MS. Food Res. Int. 2013, 51, 783-789. [CrossRef]

8. Eckenrode, B.A. Environmental and forensic applications of field-portable GC-MS: An overview. J. Am. Soc. Mass Spectrom. 2001, 12, 683-693. [CrossRef]

9. Cockburn, P. Method Development for Identification of Adulterated Spirits Using Field Portable GC/MS, Application Note, Perkin Elmer Inc., Waltham, MA. 2016. Available online: https://www.perkinelmer.com/lab-solutions/resources/docs/APP_Method-Dev-ID-Adulterated-Spiritsusing-Field-Portable-GC-MS_012711_01.pdf (accessed on 1 September 2019).

10. Reddy, S. Rapid Fingerprinting of Volatile Components in Coffee Varieties Using the Portable Torion T-9 Portable GC/MS System, Application Note, Perkin Elmer Inc., Shelton, CT. 2016. Available online: https://www.perkinelmer.com/lab-solutions/resources/docs/APP_Volatile-Components-in-Coffee_ 013202_01.pdf (accessed on 1 September 2019).

Publisher's Note: MDPI stays neutral with regard to jurisdictional claims in published maps and institutional affiliations. 